\title{
Impactos de melhorias tecnológicas, organizacionais e de transporte sobre a competitividade da fruticultura irrigada no Ceará
}

\author{
Impacts of technological, organizational, and transportation \\ improvements on the competitiveness of irrigated fruit culture in the \\ State of Ceará \\ Eliane Pinheiro de Sousa' (D), Antônio Carvalho Campos² (i) \\ ${ }^{1}$ Programa de Pós-graduação em Economia Regional e Urbana, Universidade Regional do Cariri (URCA), Crato (CE), Brasil. \\ E-mail: pinheiroeliane@hotmail.com \\ ²Programa de Pós-graduação em Economia Aplicada, Universidade Federal de Viçosa (UFV), Viçosa (MG), Brasil. E-mail: \\ accampos@ufv.br
}

\begin{abstract}
Como citar: Sousa, E. P., \& Campos, A. C. (2022). Impactos de melhorias tecnológicas, organizacionais e de transporte sobre a competitividade da fruticultura irrigada no Ceará. Revista de Economia e Sociologia Rural, 60(3), e215879.
\end{abstract} https://doi.org/10.1590/1806-9479.2021.215879

Resumo: Este trabalho avalia como melhorias tecnológicas, organizacionais e de infraestrutura de transporte podem contribuir para reduzir as diferenças de competitividade sobre os níveis de produção, renda e bem-estar dos fruticultores. Para esse fim, empregou-se um modelo aplicado de equilíbrio geral espacial. Os resultados das simulações de redução nos custos de transferência e mudança tecnológica indicaram acréscimos nas produções e reduções nos preços nas regiões beneficiadas, gerando ganhos de competitividade. Em todos os cenários analisados, os níveis de bem-estar acompanharam o sentido da alteração da renda, mas suas variações percentuais foram muito menores que as ocorridas com a renda, indicando que parcela considerável do crescimento da renda foi absorvida pela variação de preços.

Palavras-chave: formação espacial de preços, fruticultura irrigada, Ceará.

\begin{abstract}
This study assesses how technological, organizational, transportation, and infrastructure improvements can contribute to reducing differences in competitiveness in terms of the production levels, income, and well-being of fruit growers. For this purpose, an applied model of general spatial equilibrium was used. The results of simulations of transfer cost reductions and technological change indicated increases in production and price reductions in regions benefiting from them, generating competitiveness gains. In all the scenarios analyzed, well-being levels followed the direction of the change in income, but their percentage changes were much smaller than those seen in income, indicating that a considerable portion of income growth was absorbed by the variation in prices.
\end{abstract}

Keywords: spatial price formation, irrigated fruit culture, Ceará.

\section{Introdução}

Segundo Haddad (2006), intervenções espacialmente localizadas podem aumentar as vantagens competitivas de uma região. Efeitos de economias de escala e de acessibilidade permitem que a área de mercado das firmas se expanda e surjam oportunidades de acesso aos mercados de insumos mais amplos. Ademais, mudanças econômicas ocorridas em uma dada localidade ocasionam potenciais efeitos sobre outras regiões. Isto desempenha papel relevante para a avaliação dos impactos de políticas de transporte sobre as regiões de um país, tendo em vista as relações de complementaridade e competição entre os espaços econômicos relevantes.

A região Nordeste é fortemente influenciada pelas modificações que aconteceram na economia brasileira. A tradicional visão assistencialista, marcada intensamente pelas secas, é contrastada com a constituição de novas áreas modernas e dinâmicas, que foram se desenvolvendo ao longo 
do processo de desconcentração espacial da atividade econômica do país (Pequeno \& Dantas, 2007). Dentro da região Nordeste, destaca-se o estado do Ceará, que foi organizado espacialmente através dos agropolos, onde foram zoneadas as regiões com maiores potencialidades para a agricultura irrigada, com foco na exploração sustentável do setor produtivo (Rabêlo, 2006). Esse processo caracterizado pela regionalização das ações de desenvolvimento por meio da criação de seis agropolos (Baixo Acaraú, Baixo Jaguaribe, Cariri, Centro-Sul, Ibiapaba e Metropolitano) foi realizado pelo governo cearense em virtude de considerar a agricultura irrigada como uma unidade de negócio importante para o desenvolvimento do estado (Sabadia et al., 2006).

Dentre as atividades que fazem parte do setor agrícola, destaca-se a fruticultura como uma das principais geradoras de emprego, renda e desenvolvimento rural. Dados divulgados no Diário do Nordeste (2014) mostram que as frutas irrigadas respondem por 38,4 mil hectares distribuídos em seis agropolos, que abrangem 64 municípios cearenses, correspondendo a um valor bruto da produção (VBP) de $\mathrm{R} \$ 755,5$ milhões e gerando 21,6 mil empregos diretos e volume de exportações de US\$102,5 milhões.

Essas regiões apresentam estruturas produtivas e de infraestrutura distintas e se dedicam às explorações de diferentes culturas. Logo, os produtores localizados nas diferentes áreas irrigadas deparam-se com custos de transferência diferenciados tanto para insumos como para produtos, que abrangem custos de transporte, armazenagem, manuseio do produto e financeiros. Além da infraestrutura de transporte, existem outros vetores estruturantes, como a tecnologia e a organização da produção, que são fundamentais para fortalecer a competitividade das áreas irrigadas cearenses. Esses fatores podem estar associados com a distribuição espacial da produção e com os sistemas de determinação espacial de preços existentes para insumos e produtos nessas regiões. Tais processos de determinação espacial dos preços apresentam características que fogem à competição perfeita. Os produtores submetem-se aos oligopólios na compra de insumos modernos e aos oligopsônios na venda das frutas produzidas nessas áreas irrigadas.

Em face do exposto, cabe mencionar que se reveste de importância a realização de estudos que identifiquem ações de políticas públicas, como melhorias das condições de transporte, tecnológicas e organizacionais, para minimizar imperfeições existentes, gerando maior atratividade de investimentos em locais menos competitivos. Nesse âmbito, a contribuição do estudo se assenta não apenas como forma de fornecer informações aos fruticultores, como também propiciar melhores condições de transporte e tecnologias mais sofisticadas; e servir de referência para outras pesquisas que utilizem a metodologia proposta.

O principal insight econômico da pesquisa é impulsionar o progresso tecnológico por intermédio da adoção de tecnologias mais eficientes, que sejam poupadoras de mão de obra e insumos, como a técnica de fertirrigação; o aperfeiçoamento da estrutura organizacional por meio de associações, cooperativas ou outro formato de networks sociais que contribuam para aumentar o poder de barganha dos produtores, tornando menos dependentes das decisões tomadas nas estruturas oligopolistas e oligopsonistas; e melhores condições de transporte, visto que investimentos em infraestrutura de transporte, como construção e recuperação da malha rodoviária, reduzem os custos para transferir produtos entre regiões e expandem as oportunidades de acesso aos mercados em uma dada localidade. Essas ações permitem reduzir as imperfeições existentes na compra de insumos modernos e na venda das frutas produzidas nas áreas irrigadas, de modo a promover um desenvolvimento mais equilibrado em tais regiões buscando fortalecer a competitividade dessas localidades, mediante o crescimento nos níveis de produção e diminuição nos preços nas regiões beneficiadas, podendo 
potencialmente ampliar a rentabilidade das atividades produtivas e melhorar os padrões de vida das populações residentes.

A melhoria das condições de transporte contribui para reduzir o tempo de viagem que liga uma dada região ao ponto-base, com consequente redução das diferenças em competitividade entre as atividades produtivas dessas áreas irrigadas cearenses, resultante das diferenças dos custos de transferência. Essa diferenciação dos custos de transferência está relacionada às diferentes distâncias entre as áreas de produção dessas regiões, dispersas espacialmente, e o ponto-base, situado na capital cearense, que constitui o local de destino dos produtos. Para Haddad et al. (2011), os investimentos em infraestrutura de transporte reduzem os custos de transação e ampliam as oportunidades em uma região, podendo potencialmente expandir os rendimentos e melhorar os padrões de vida das populações residentes.

Portanto, este trabalho se propõe avaliar como melhorias tecnológicas, organizacionais e de transporte podem contribuir para reduzir as diferenças de competitividade entre as atividades produtivas desenvolvidas nas regiões de fruticultura irrigada no Ceará. Nesse contexto, ressalta-se que o conceito de competitividade utilizado neste trabalho consiste na alocação eficiente dos recursos, podendo ser medida pela rentabilidade das atividades produtivas e que a competitividade relativa diz respeito à rentabilidade auferida com a comercialização de produtos similares produzidos nas diferentes áreas irrigadas.

\section{Referencial Teórico}

Tendo em vista que a atividade frutícola cearense está localizada em diferentes áreas irrigadas, a dimensão espacial deve ser considerada. Portanto, a literatura econômica que discorre sobre as teorias da localização reveste-se de importância para este estudo. Para Haddad (1989), as teorias da localização podem ser classificadas em dois grupos. No primeiro, encontram-se as que consideram que os mercados consumidores se concentram em pontos discretos do espaço geográfico, cujas contribuições seminais foram dadas por Von Thünen e Weber e, no segundo, as que consideram que os consumidores estejam dispersos em áreas de mercado, nos quais Hotelling, Lösch e Hoover deram suas contribuições seminais.

No presente estudo, o mercado consumidor das frutas produzidas nas áreas irrigadas sob análise está concentrado no ponto-base, ou seja, ele é considerado puntiforme, então as teorias pertencentes ao primeiro grupo, que se concentram na minimização dos custos de transferência, são as que interessam nessa pesquisa. Dentre essas, centrou-se na teoria de Von Thünen, que se destina ao estudo da localização agrícola. O principal interesse dessa teoria consiste em analisar como a terra deveria ser alocada de forma competitiva entre os múltiplos usos, visto que o produto agrícola tem que ser transferido da área de produção para o centro consumidor. O modelo em sua versão tradicional assume que as produtividades dos fatores capital e trabalho, assim como o custo de produzir um dado produto agrícola são idênticos em todas as localidades (Greenhut et al., 1987). Conforme Kellerman (1989), porém, diante de situações de diferenciação espacial de preços, diferenciação nos preços do frete com variação da distância, presença de policulturas e informações imperfeitas, os anéis de Von Thünen deixam de apresentar a configuração geométrica de círculos concêntricos. O relaxamento das pressuposições clássicas é corroborado por Clemente \& Higachi (2000), que ressaltam que essa configuração somente é possível dentro de hipóteses restritivas, como presença de uma região fechada, em que se admite apenas um único mercado, cujo espaço seja homogêneo em termos da fertilidade do solo e da facilidade de movimentos, ignorando variações nos custos de produção e de transporte. 
Portanto, no presente trabalho, mesmo reconhecendo o importante papel desempenhado pelos fundamentos da teoria da localização agrícola, adotou-se uma versão generalizada dessa teoria, cujos pressupostos foram relaxados, incorporando imperfeições no mercado, tendo em vista que as regiões cearenses de fruticultura irrigada apresentam custos de transferência distintos. É relevante destacar ainda que a adoção de tecnologias eficientes em um dado ponto do espaço propicia aumento em sua produtividade, o que gera menores custos unitários, tornando as atividades mais competitivas. Assim, o progresso tecnológico assume uma função imprescindível no sentido de reduzir as diferenças de competitividade entre as atividades produtivas desenvolvidas nas regiões de fruticultura irrigada.

Além do embasamento teórico concernente aos modelos clássicos de localização, os modelos da Nova Geografia Econômica (NGE) também contribuíram de forma expressiva com questões locacionais, podendo-se destacar os estudos de Krugman (1991); Krugman \& Venables (1996); e Fujita et al. (1999). Segundo esses autores, o arcabouço teórico da NGE considera os retornos crescentes de escala e a concorrência imperfeita para explicar a distribuição espacial das atividades. A concentração de algumas indústrias nas regiões é explicada mediante a atuação das forças de concentração centrípetas e das forças de desconcentração centrífugas.

Ademais, o estudo requer o embasamento sobre a diferenciação espacial de preços. Para Greenhut et al. (1987) e Edwards (2007), a diferenciação espacial de preço existe quando a diferença em preços incluindo custos de transferência entre qualquer par de mercados não for igual à diferença em custos de transporte incorridos pela empresa que oferta nesses mercados. Existem diversas práticas espaciais de preços que são provenientes das diferentes distâncias que separam os produtores de seus clientes. Dentre elas, a literatura econômica destaca o preço uniforme FOB (preço de fábrica) e o preço de entrega incluindo custos de transferência (delivered pricing) que pode ser uniforme ou preço do ponto-base.

Em relação ao sistema de preço de entrega incluindo custos de transferência uniforme, tem-se que cada firma cobra o mesmo preço para todos os consumidores. É o que acontece quando firmas estabelecem preços uniformes dentro de zonas, cujas distâncias e os custos de transferência não variam muito (Espinosa, 1992). Quanto ao preço de ponto-base, para Haddock (1982), é estabelecido na base para um produto idêntico. Por exemplo, o preço de uma dada fruta i em uma dada área irrigada j está baseado no preço vigente no ponto-base. Os produtores aceitam esse preço e não têm poder de barganha para influenciá-lo.

Com base nesse sistema de precificação, todos os preços são cotados como o preço de fábrica anunciado naquele ponto, inclusive o frete para o destino, e independe da localização do vendedor. Essa prática penaliza os clientes próximos ao ponto-base, já que eles são discriminados pela cobrança de fretes "fantasmas", que correspondem à taxação de custos de transferência fictícios. Tal situação não ocorreria se eles pudessem escolher uma forma de pagamento em que a remuneração do produto e a cobrança do frete fossem separadas. Inversamente, os custos do frete envolvidos no transporte dos produtos para os clientes situados mais distantes são absorvidos pelos vendedores (Khemani \& Shapiro, 1993).

A situação descrita de sistema de preço do ponto-base geralmente está presente na estrutura de oligopólio espacial conforme Scherer (1980). Para Graubner et al. (2011), porém, o poder de oligopsônio em alguns mercados de matérias-primas e/ou produtos agrícolas pode ser mais importante que o poder de oligopólio, correspondendo ao mercado à jusante.

Os relacionamentos expressos nessa situação de diferenciação de custos de transferência são os que mais se assemelham às condições vigentes nas áreas de fruticultura irrigada para a determinação dos fluxos de mercadorias entre regiões, pois o que se observa é a presença de poucos compradores que adquirem a produção de frutas dessas áreas irrigadas, estabelecendo 
o preço praticado no ponto-base. Essas situações são passíveis de serem modeladas por meio de uma estrutura analítica de equilíbrio geral que permite estabelecer as diversas interdependências entre as atividades produtivas e, consequentemente, as influências de fatores determinantes das diferenças de competitividade entre essas atividades regionais.

Em termos de evidências empíricas recentes que aplicaram essa abordagem analítica, podem-se destacar os estudos de Haddad et al. (2011), Vassallo (2015), Campos \& Haddad (2016) e Elshahawany et al. (2017). Esses estudos procuraram avaliar os impactos da infraestrutura de transporte, porém não consideraram especificamente o mercado de frutas. O presente trabalho contribui também no sentido de avaliar os impactos de outros fatores sobre a competitividade, como tecnologias mais eficientes e melhorias organizacionais, uma vez que não foi alvo de discussão nesta literatura especializada.

\section{Metodologia}

\subsection{Modelo analítico}

Os modelos aplicados de equilíbrio geral com dimensão regional acrescidos de um tratamento explícito dos custos de transportes originaram os modelos aplicados de equilíbrio geral espaciais (Almeida, 2003). Segundo Araújo (2006), a utilização desses modelos é adequada quando o enfoque do estudo é a infraestrutura de transporte e sua influência na questão das desigualdades regionais, com o intuito de possibilitar uma análise do relacionamento entre as regiões de estudo. Desta forma, como se pretende mensurar os efeitos das diferenças dos custos de transferência entre as diversas áreas irrigadas cearenses, empregou-se tal modelagem nesse trabalho.

Conforme Almeida (2003), existem três formas de se incorporar explicitamente os custos de transporte no modelo aplicado de equilíbrio geral espacial. A primeira consiste na adoção do pressuposto de custos de transporte do tipo iceberg, proposto por Samuelson. Isto significa que uma parte do produto transportado se dissipa no próprio processo de transporte (como um iceberg avançando além-mar). Assim, chega-se ao destino com uma quantidade menor do produto, já que parcela dele foi transformada em custo de transporte. Esse tipo de modelagem foi adotado no contexto internacional por Bröcker et al. (2010); e Sakamoto (2012) e, em termos nacionais, por Almeida (2003) e Almeida \& Guilhoto (2007).

Para a segunda, os serviços de transporte são produzidos por um setor de transporte otimizador, que se baseia na minimização de seus custos. Tais serviços e custos relacionados com o deslocamento de produtos com base em pares de origem e destino seriam modelados de forma explícita. Sua calibração considera o custo de transporte específico de cada fluxo de produto, gerando diferenciação espacial de preços. Essa abordagem foi utilizada, na literatura internacional, por Lofgren \& Robinson (2002), Haddad et al. (2011) e Elshahawany et al. (2017) e, no Brasil, por Haddad (2004), Vassallo (2015) e Campos \& Haddad (2016).

A terceira consiste em determinar um índice de acessibilidade nesse modelo de transporte estruturado exogenamente para ser incluído na função de produção do modelo de equilíbrio geral. Na literatura internacional que aplicou essa abordagem, pode-se citar Kim \& Hewings (2003). Um exemplo da adoção dessa forma de especificação no Brasil pode ser encontrado no trabalho realizado por Araújo (2006).

Considerando os modelos apresentados, verifica-se que as características pertencentes à segunda forma correspondem ao contexto desse estudo, sendo condizente com seus propósitos. Logo, foi a modelagem empregada nesse trabalho. 


\subsubsection{Abordagem matemática}

Nesta seção são apresentadas as principais equações comportamentais consistentes com a Matriz de Contabilidade Social - MCS (Quadro 1) dessa economia regional. Essas equações assumem o formato CES, porém pode-se empregar o formato Leontief quando a elasticidade de substituição for zero e Cobb-Douglas quando seu valor for um. Tais equações expressas de (1) a (9) contêm variáveis endógenas, indicadas por letras maiúsculas, variáveis exógenas, por letras minúsculas e parâmetros, por letras gregas, cujos subscritos $i(i=1, \ldots, 9)$ referem-se às diferentes frutas e $j(j=1, \ldots, 6)$ diz respeito às áreas irrigadas.

A função de produção $\left(F P_{i j}\right)$ foi modelada por uma função CES, mediante o uso dos fatores terra $(N)$, trabalho $(L)$, transporte $(T)$ e outros insumos $(I)$. O fator terra foi considerado fixo em cada região, mas pode ser empregado para o cultivo de diferentes frutas produzidas dentro da área irrigada e os demais fatores são móveis entre atividades dispersas espacialmente entre regiões, como expressa pela Equação 1:

$F P_{i j}=\varepsilon_{i j}\left[\delta_{i j 1} N^{\frac{\sigma_{i j}-1}{\sigma_{i j}}}+\delta_{i j 2} L^{\frac{\sigma_{i j}-1}{\sigma_{i j}}}+\delta_{i j 3} T^{\frac{\sigma_{i j}-1}{\sigma_{i j}}}+\delta_{i j 4} I^{\frac{\sigma_{i j}-1}{\sigma_{i j}}}\right]^{\frac{\sigma_{i j}}{\sigma_{i j}-1}}$

em que $\varepsilon_{i j}$ é o parâmetro tecnológico da função; $\delta_{i j}$ é o parâmetro de distribuição da função; e $\sigma_{i j}$ é a elasticidade de substituição entre uma dada fruta e as áreas irrigadas. Além disso, tem-se que $\sum_{n=1}^{4} \delta_{i j n}=1$, no qual $n$ indica os fatores empregados.

A disponibilidade total de trabalho $\left(D L_{j}\right)$ foi definida como função CES da disponibilidade de mão de obra, que é rateada para cada região de fruticultura irrigada, conforme indicada pela Equação 2:

$D L_{j}=\eta_{j}\left[\sum_{j=1}^{\sigma} \lambda_{j} D L_{j}^{\rho}\right]^{1 / \rho}$

em que $\eta_{j}$ é o parâmetro tecnológico da função; $\lambda_{j}$ é o parâmetro de distribuição da função e $\rho$ é o parâmetro de substituição da função CES.

A disponibilidade total de transporte $\left(D T_{j}\right)$ foi caracterizada como função CES da disponibilidade de transporte, distribuída para cada área irrigada, como representada pela Equação 3:

$D T_{j}=\alpha_{j}\left[\sum_{j=1}^{6} \varphi_{j} D T_{j}^{\rho}\right]^{1 / \rho}$

em que $\alpha_{j}$ é o parâmetro tecnológico da função; $\varphi_{j}$ é o parâmetro de distribuição da função; e $\rho$ é o parâmetro de substituição da função CES.

A disponibilidade total de insumos $\left(D I_{j}\right)$ foi definida como função CES da disponibilidade de insumos, alocada para cada região, conforme indicada pela Equação 4:

$$
D I_{j}=\beta_{j}\left[\sum_{j=I}^{6} \gamma_{j} D I_{j}^{\rho}\right]^{1 / \rho}
$$

em que $\beta_{j}$ é o parâmetro tecnológico da função; $\gamma_{j}$ é o parâmetro de distribuição da função; e $\rho$ é o parâmetro de substituição da função CES.

Além dessas disponibilidades, é relevante ressaltar a disponibilidade total de frutas $\left(D F_{i}\right)$ como função da disponibilidade de frutas de cada área irrigada, modelada por meio de uma função CES, estando expressa pela Equação 5:

$$
D F_{i}=\mu_{i}\left[\sum_{i=1}^{g} \psi_{i} D F_{j}^{\rho}\right]^{1 / \rho}
$$


em que $\mu_{i}$ é o parâmetro tecnológico da função; $\psi_{i}$ é o parâmetro de distribuição da função e $\rho$ é o parâmetro de substituição da função CES.

A renda total dos fatores $\left(R T F_{i j}\right)$ foi expressa pela soma das remunerações da terra $\left(R N_{i j}\right)$, salários $\left(R L_{i j}\right)$, transferências $\left(R T_{i j}\right)$ e insumos $\left(R I_{i j}\right)$, como apresentada pela Equação 6:

$R T F_{i j}=R N_{i j}+R L_{i j}+R T_{i j}+R I_{i j}$

em que a renda de cada um desses fatores pode ser dada como função do produto do somatório do preço médio e da demanda de cada fator.

Os preços das frutas adotados no ponto-base $\left(P_{i}\right)$ foram representados por funções dos preços externos $\left(p w_{i}\right)$, definidos fora da economia regional, exógenos e ajustados pelas taxas de comercialização $\left(t_{c}\right)$, como mostrado pela Equação 7:

$P_{i}=p w_{i}\left(1+t_{c}\right)$

Como se observa pela MCS (Quadro 1), o equilíbrio no mercado de frutas ocorre quando a demanda e a oferta de frutas tiverem o mesmo valor para cada setor produtivo considerado. Da mesma forma, o equilíbrio no mercado de fatores foi obtido conforme indicado na Equação 8:

$\sum_{i j} D T F_{i j}=f s$

em que ${ }_{D T F}$ é a demanda total por fatores e $f S$ são as dotações de fatores primários, que são fixadas exogenamente.

Por fim, a função utilidade, que capta o bem-estar dos agentes considerados, foi expressa pela variação equivalente (VE) associada a um dado choque exógeno, conforme Almeida (2003), Haddad (2004) e Vassallo (2015). Para tais autores, a VE refere-se à mudança monetária no nível de renda inicial que um agente representativo necessitaria para alcançar o novo nível de utilidade, supondo os preços vigentes no equilíbrio inicial. Em termos específicos, para funções de utilidade homogêneas lineares, a VE pode ser expressa pela Equação 9:

$V E^{w}=\sum_{w=l}^{9}\left(\frac{U_{l}^{w}-U_{0}^{w}}{U^{w}}\right) I^{w}$

em que $U_{I}^{w}$ é o nível de utilidade após a mudança da política, $U_{0}^{w}$ é o nível de utilidade contrafactual (antes do choque exógeno), I é a renda disponível referencial aos preços referenciais e o sobrescrito $w$ refere-se aos consumidores.

Neste trabalho, foram considerados nove consumidores, sendo que $w_{1}$ a $w_{6}$ referem-se ao bem-estar do fruticultor representativo de cada área irrigada (Baixo Acaraú, Baixo Jaguaribe, Cariri, Centro-Sul, Ibiapaba e Metropolitana); $w_{7}$, bem-estar do trabalhador; $w_{8}$, bem-estar do transportador; e $w_{9}$, bem-estar do fornecedor de insumos. Se o VE apresentar valores positivos, há melhorias no bem-estar; caso contrário, verifica-se que há perda de bem-estar. Nesse sistema de equações, os fundamentos microeconômicos devem ser compatibilizados com o fechamento macroeconômico do modelo. Além disso, na escolha das formas funcionais, deve-se levar em consideração sua aderência à realidade com o intuito de viabilizar a análise empírica.

Essas funções caracterizam formas de produção que se situam diante de estruturas de mercado, como o oligopsônio, para comercialização das frutas, e oligopólio, para compra de insumos modernos. As imperfeições dos mercados foram contidas nas diferentes valorações atribuídas para a absorção do frete e/ou custos de frete "fantasma", que foram relacionados com as diferentes distâncias entre as regiões de fruticultura irrigada e o ponto-base. 
Nesse contexto, é relevante destacar que apesar de o modelo aplicado de equilíbrio geral espacial utilizado neste trabalho apresentar essas imperfeições de mercado, elas foram incorporadas nos custos de transferência diferenciados e não inviabilizaram a adoção das pressuposições competitivas, indicando que, no equilíbrio, a solução do modelo fornece um conjunto de preços que equilibram todos os mercados de produtos e de fatores, possibilitando que todas as otimizações dos agentes econômicos sejam atendidas. Como os preços considerados nesse modelo foram relativos, definiu-se um numerário. Neste estudo, todos os preços da economia regional foram expressos em relação ao índice de preços do agente de comercialização, sendo considerado como o numerário do modelo. A escolha desse numerário deve-se ao fato de que essa variável interage com todos os produtores de frutas.

De posse do banco de dados compilado na MCS regional (Quadro 1) e da escolha das formas funcionais que expressam o comportamento de cada agente econômico representativo, realizou-se a calibração para calcular os valores para seus parâmetros. O processo de calibração considerou o custo de transferência específico de cada fluxo de produto, registrado na MCS, já que a modelagem adotada nesse trabalho admite que os serviços de transporte sejam produzidos por um setor de transporte otimizador.

Após testar diversas magnitudes para as elasticidades de substituição constante (CES), verificou-se que a forma funcional Cobb-Douglas reproduziu os dados do ano-base como uma solução de equilíbrio desse modelo, sendo, portanto, utilizada na calibração do modelo. Com base nessas especificações, obtém-se o equilíbrio inicial, que constitui o benchmark utilizado como referência para comparar com as simulações da análise e para verificar seus impactos sobre níveis de produção e bem-estar.

Para resolver o sistema de equações que fizeram parte do modelo aplicado de equilíbrio geral para o ano-base, deve-se atentar para o tipo de fechamento adotado. Como esse modelo contém um número de variáveis que excede o de equações, o fechamento consiste em identificar as variáveis exógenas e endógenas, porém essa escolha está vinculada à concepção teórica que se pretende dar ao modelo, além dos aspectos teóricos relevantes que definem as estruturas das economias. Neste estudo, considerou-se o fechamento neoclássico, em que as receitas recebidas com a venda das frutas foram utilizadas para o pagamento dos fatores. Com relação ao mercado de trabalho, verificou-se que o equilíbrio ocorreu quando a oferta de mão de obra foi idêntica à sua demanda em todos os mercados. Portanto, com base nessa forma de fechamento, se houver algum desequilíbrio, os salários se ajustam para que o equilíbrio seja restabelecido.

A operacionalização do modelo foi feita mediante o uso da linguagem do MPSGE (Mathematical Programming System for General Equilibrium), que faz parte do software GAMS (General Modelling System). Embora o modelo adotado nesse estudo possa ser aplicado para modelar sub-regiões, não se utilizaram dados de uma matriz de insumo-produto inter-regional. Esse procedimento não foi adotado, visto que não se buscou extrapolar os impactos dessas atividades em estudo sobre as demais atividades regionais, nem na determinação dos encadeamentos para frente e para trás de seus efeitos multiplicadores. O principal interesse foi avaliar como melhorias das condições de transporte, tecnológicas e organizacionais podem contribuir para minimizar imperfeições de mercado sobre os níveis de produção e bem-estar dos fruticultores, gerando maior atratividade de investimentos em locais menos competitivos.

\subsection{Base e fonte dos dados}

A estruturação do modelo aplicado de equilíbrio geral espacial, empregado nesse trabalho, requer o conhecimento das características regionais e dos fluxos comerciais, descritos na Tabela 1 e Figura 1. 
Tabela 1 - Desagregação regional e interações comerciais

\begin{tabular}{|c|c|c|c|c|c|}
\hline & $\begin{array}{l}\text { Regiões } 1 \\
\text { a } 6\end{array}$ & $\begin{array}{c}\text { Ofertador } \\
\text { de Mão de } \\
\text { obra }\end{array}$ & $\begin{array}{l}\text { Ofertador } \\
\text { de } \\
\text { Transporte }\end{array}$ & $\begin{array}{l}\text { Ofertador } \\
\text { de Insumos }\end{array}$ & $\begin{array}{c}\text { Ponto-Base/Setor } \\
\text { Externo }\end{array}$ \\
\hline $\begin{array}{l}\text { Produtores } \\
\text { agrícolas }\end{array}$ & $\mathrm{PR}\left({ }^{*}\right)$ & Nenhum & Nenhum & Nenhum & Nenhum \\
\hline Fatores & Terra & Trabalho & Transporte & $\begin{array}{l}\text { Outros } \\
\text { insumos }\end{array}$ & Fator fictício \\
\hline Atividades & $\begin{array}{l}\text { Produção de } \\
\text { frutas }\end{array}$ & $\begin{array}{l}\text { Oferta de } \\
\text { trabalho }\end{array}$ & $\begin{array}{l}\text { Transporte de } \\
\text { frutas }\end{array}$ & $\begin{array}{l}\text { Venda de } \\
\text { insumos }\end{array}$ & $\begin{array}{l}\text { Comercialização de } \\
\text { frutas }\end{array}$ \\
\hline $\begin{array}{l}\text { Ofertador de } \\
\text { serviços de } \\
\text { transporte }\end{array}$ & Não & Não & Sim & Não & Não \\
\hline $\begin{array}{l}\text { Ofertador de } \\
\text { insumos }\end{array}$ & Não & Não & Não & Sim & Não \\
\hline $\begin{array}{l}\text { Parceiros } \\
\text { comerciais }\end{array}$ & Ponto-base & Regiões 1 a 6 & Regiões 1 a 6 & Regiões 1 a 6 & Regiões 1 a 6 \\
\hline
\end{tabular}

Fonte: Adaptado de Lofgren \& Robinson (2002, p. 656). $\left(^{*}\right)$ PR = produtor representativo.

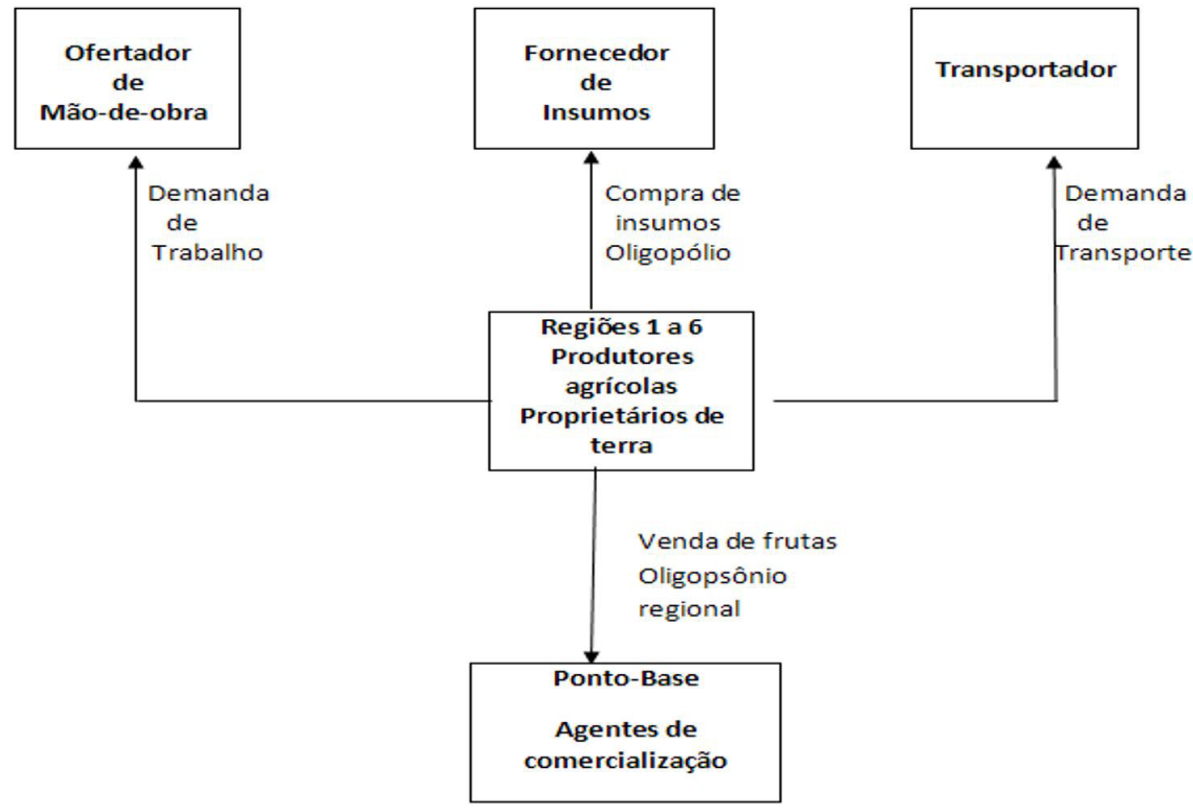

Figura 1 - Diagrama com a estruturação do modelo empregado.

Nesse contexto, foram consideradas sete regiões, sendo que seis representam as áreas cearenses de fruticultura irrigada e a sétima refere-se ao ponto-base, situado na capital cearense. Quanto aos produtores de frutas, foram consultados 150, sendo que essa amostra foi distribuída para cada região de acordo com a área em hectares destinada ao plantio irrigado de frutas. Com base nas informações fornecidas por Oliveira (2009), as regiões do Baixo Acaraú, Baixo Jaguaribe, Cariri, Centro-Sul, Ibiapaba e Metropolitana tinham, respectivamente, 2.182 13.145, 1.889; 926, 6.778 e 4.061 hectares de frutas irrigadas. Portanto, entrevistaram-se 11 fruticultores do Baixo Acaraú, 68 do Baixo Jaguaribe, 10 do Cariri, 5 do Centro-Sul, 35 da Região da Ibiapaba e 21 da Região Metropolitana. Desta forma, o produtor representativo de cada região foi obtido pela média dos dados desses fruticultores pesquisados em cada área 
irrigada. Esse produtor de frutas representativo possui dotação de terra, considerada fixa entre as áreas irrigadas, e interage com os agentes ofertadores de trabalho, transporte, insumos e os agentes de comercialização externo de frutas. Tal agente de comercialização, representativo do ponto-base, funciona como um elo das negociações comerciais entre as áreas irrigadas com o setor externo ${ }^{1}$ dessa economia regional. Não se verificam transações comerciais diretas dos fruticultores com esse mercado externo, logo tais produtores não têm poder de influenciar os preços anunciados pelo ponto-base.

O agente ofertador de trabalho distribui a mão de obra para os diversos setores produtivos das regiões de fruticultura irrigada, conforme os requerimentos de mão de obra de cada área irrigada. Da mesma forma, os serviços de transporte e outros insumos são vendidos pelos agentes que detêm esses fatores para os fruticultores de todas as áreas irrigadas com base em suas necessidades. Cada um desses agentes busca maximizar sua dotação de fatores.

As vendas das frutas para o agente de comercialização, localizado no ponto-base, geram receitas que são utilizadas para pagamentos dos outros insumos e serviços dos fatores empregados na produção e nos custos de transferência dos produtos de cada uma das regiões de fruticultura irrigada. As receitas excedentes aos pagamentos efetuados constituem as receitas líquidas de cada uma dessas áreas irrigadas. A ordenação dessas receitas líquidas permitiu a comparação das rentabilidades.

A base desses dados foi estruturada na forma de uma Matriz de Contabilidade Social (MCS). Os fluxos de renda e de bens de uma economia foram representados de modo completo e consistente na MCS, o que evidencia a interdependência existente entre os agentes envolvidos no funcionamento do sistema econômico.

Para se obter os dados requeridos na MCS, realizou-se a pesquisa de campo junto aos agentes rurais, técnicos agrícolas, engenheiros agrônomos, produtores de frutas, dirigentes de empresas, presidentes de associações e secretários de agricultura.

A MCS da economia regional tratada neste trabalho foi constituída pelas contas: atividades (produção de frutas em cada uma das seis regiões de fruticultura irrigada), fatores (terra, trabalho, transporte e outros insumos) e agentes (produtores de frutas, ofertador de trabalho, transportador e fornecedor de insumos), referente ao ano de 2007. Essa MCS não incorporou dados sobre a economia externa a essas regiões.

Pela ótica das colunas, que indicam as despesas, verifica-se que as atividades adquirem insumos e fatores de produção e a equalização entre valor das vendas e das compras foi realizada pela aquisição de uma dotação de fatores fictícios (Fx_F) junto ao agente de comercialização externa. Em contrapartida, as atividades produtoras de frutas recebem receitas provenientes das vendas de frutas aos diversos agentes, de modo que tais atividades possam fazer frente às despesas com as compras de insumos e de fatores. Essa MCS apresenta formato de uma matriz quadrada, no qual o total das linhas é igual ao total das colunas em cada segmento (Quadro 1). Segundo Vieira (1998), porém, se essa matriz for construída como base de dados para os modelos aplicados de equilíbrio geral e o software a ser empregado for o MPSGE/GAMS, a MCS pode deixar de ter o formato de matriz quadrada e passar para o formato de matriz retangular, com a manutenção dos dados da matriz quadrada original. Na forma retangular, as somas das colunas e das linhas são nulas, se a matriz estiver balanceada.

1 Corresponde ao setor fora da área constituída pelas regiões de fruticultura irrigada. 
Quadro 1 - Representação condensada da Matriz de Contabilidade Social

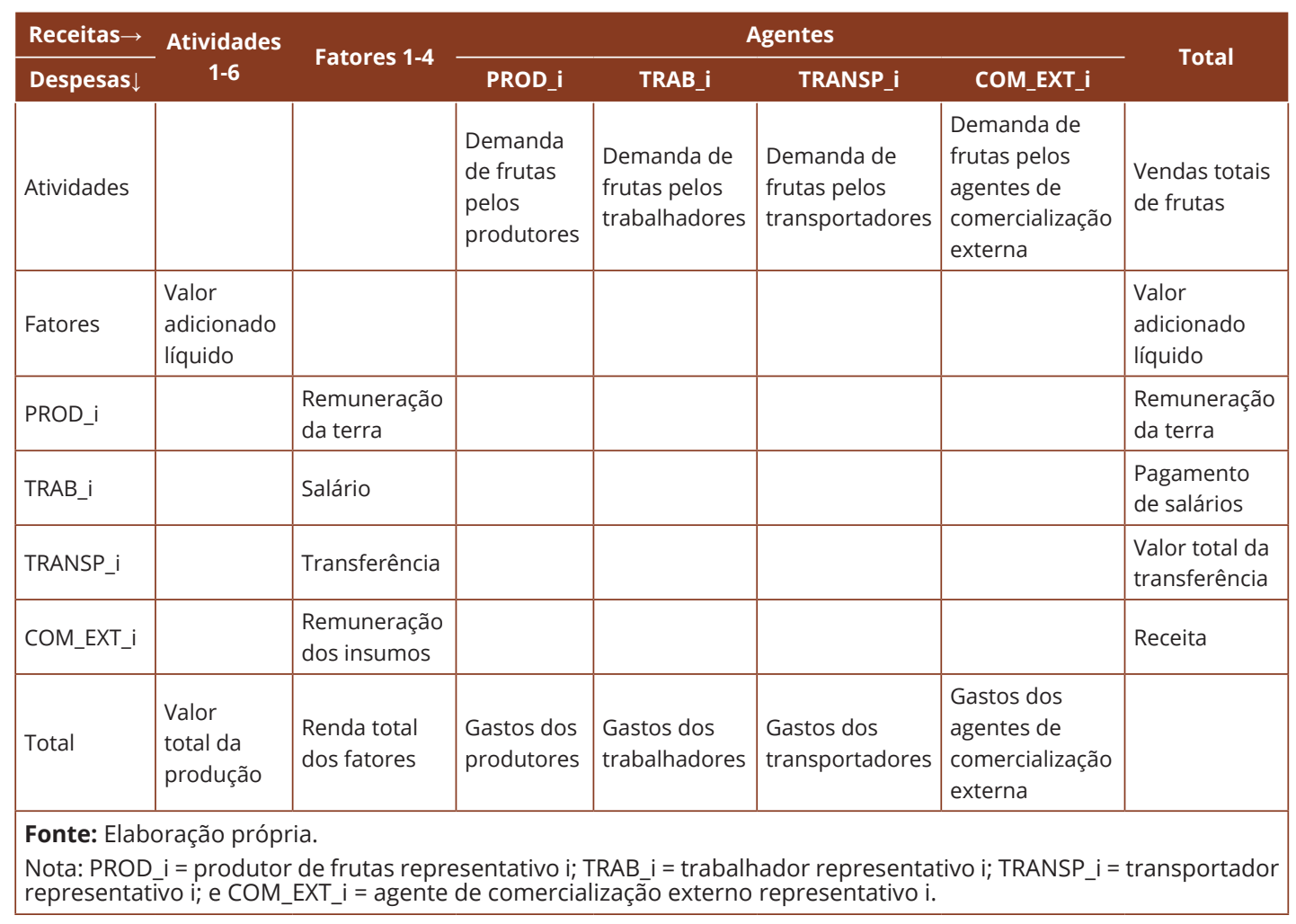

\section{3. Áreas de estudo}

Para se obter as informações contidas na MCS, as seis regiões cearenses de fruticultura irrigada foram visitadas durante os meses de janeiro e fevereiro de 2009, cujos dados foram coletados para os três últimos anos que antecederam a pesquisa de campo (2006, 2007 e 2008), mas se considerou o ano de 2007 como ano-base desta pesquisa, visto que, para delimitar as áreas de estudo analisadas, que se encontram na Tabela 2, foram considerados dados do IBGE/ SDA/Instituto Agropolos, elaborados pela Agência de Desenvolvimento Econômico do Ceará (ADECE) referentes a 2007. Segundo Oliveira (2009), 82,3\% do plantio irrigado cearense de frutas concentram-se no Baixo Acaraú, Baixo Jaguaribe, Cariri, Centro-Sul, Ibiapaba e Metropolitana. Dada a expressividade da fruticultura irrigada dessas regiões cearenses, elas foram escolhidas para compor a área de estudo deste trabalho, cujas características se encontram na Tabela 2.

Tabela 2 - Principais características das diferentes regiões cearenses consideradas

\begin{tabular}{|c|c|c|c|c|}
\hline $\begin{array}{l}\text { Regiōes } \\
\text { cearenses }\end{array}$ & $\begin{array}{c}N^{0} \text { de } \\
\text { municípios } \\
\text { (a) }\end{array}$ & $\begin{array}{c}\text { Área } \\
\text { irrigada } \\
\text { (ha.) }^{\text {(a) }}\end{array}$ & $\begin{array}{l}\text { PIB total (R\$ } \\
\text { mil) (b) }\end{array}$ & Cadeias produtivas principais (a) \\
\hline Baixo Acaraú & 14 & 3.237 & $1.890 .951,00$ & $\begin{array}{l}\text { Abacaxi, coco, goiaba, mamão, } \\
\text { manga, maracujá, melão, pimenta } \\
\text { e uva. }\end{array}$ \\
\hline
\end{tabular}

Fontes: (a) IBGE/SDA/Instituto Agropolos, elaborado pela ADECE, referentes a 2007 (Oliveira, 2009); e (b) elaboração própria com base nos dados do IPECE - Perfil Básico Municipal (2007). 
Tabela 2 - Continuação...

\begin{tabular}{|c|c|c|c|c|}
\hline $\begin{array}{l}\text { Regiões } \\
\text { cearenses }\end{array}$ & $\begin{array}{l}N^{\circ} \text { de } \\
\text { municípios } \\
\text { (a) }\end{array}$ & $\begin{array}{l}\text { Área } \\
\text { irrigada } \\
\text { (ha.) }^{\text {(a) }}\end{array}$ & $\begin{array}{l}\text { PIB total (R\$ } \\
\text { mil) }^{(b)}\end{array}$ & Cadeias produtivas principais ${ }^{\text {(a) }}$ \\
\hline $\begin{array}{l}\text { Baixo } \\
\text { Jaguaribe }\end{array}$ & 15 & 24.900 & $1.457 .310,00$ & $\begin{array}{l}\text { Abacaxi, ata, banana, goiaba, } \\
\text { graviola, mamão, manga, melão, } \\
\text { melancia, uva e hortaliças. }\end{array}$ \\
\hline Cariri & 8 & 5.232 & $1.506 .998,00$ & $\begin{array}{l}\text { Banana, goiaba, manga, uva, } \\
\text { hortaliças, plantas e flores tropicais. }\end{array}$ \\
\hline Centro-Sul & 4 & 7.583 & $402.859,00$ & Banana, goiaba. \\
\hline Ibiapaba & 9 & 10.509 & $686.592,00$ & $\begin{array}{l}\text { Acerola, maracujá, hortaliças, flores } \\
\text { tropicais, temperadas, folhagens e } \\
\text { rosas. }\end{array}$ \\
\hline Metropolitana & 14 & 12.883 & $5.345 .379,00$ & $\begin{array}{l}\text { Ata, banana, coco, graviola, mamão } \\
\text { e flores tropicais. }\end{array}$ \\
\hline $\begin{array}{l}\text { Outras } \\
\text { regiões }\end{array}$ & 120 & 13.034 & & \\
\hline Ceará & 184 & 77.378 & $33.260 .672,00$ & $\begin{array}{l}\text { Abacaxi, banana, mamão, manga, } \\
\text { melão, melancia sem sementes, uva, } \\
\text { hortaliças e produtos da floricultura. }\end{array}$ \\
\hline
\end{tabular}

Fontes: (a) IBGE/SDA/Instituto Agropolos, elaborado pela ADECE, referentes a 2007 (Oliveira, 2009); e (b) elaboração própria com base nos dados do IPECE - Perfil Básico Municipal (2007).

Para representar a fruticultura irrigada do Baixo Acaraú, considerou-se o Perímetro Irrigado Baixo Acaraú do Departamento Nacional de Obras contra as Secas (DNOCS) como representativo da região. Esse perímetro irrigado está localizado no norte cearense, abrangendo áreas dos municípios de Acaraú, Bela Cruz e Marco, e distam 220 km da capital. A fruticultura irrigada do Baixo Jaguaribe foi representada pelo Perímetro Irrigado Tabuleiros de Russas, localizado nos municípios de Russas, Limoeiro do Norte e Morada Nova, e o Perímetro Irrigado Jaguaribe Apodi, que se encontra na Chapada do Apodi, mais precisamente no município de Limoeiro do Norte (Departamento Nacional de Obras Contra as Secas, 2009). O município de Mauriti, localizado no sul cearense, foi considerado como representativo da fruticultura irrigada do Cariri. Segundo o Departamento de Edificações e Rodovias (2009), a distância desse município para a capital cearense é de $492 \mathrm{~km}$. Para representar a fruticultura irrigada do Centro-Sul, considerou-se o município de Iguatu como representativo dessa região. Conforme dados do Departamento de Edificações e Rodovias (2009), esse município dista 384 km da capital cearense. Quanto à fruticultura irrigada da Ibiapaba, os municípios de Ubajara e Tianguá foram considerados como representativos. A distância média desses municípios para Fortaleza é de 333 km, conforme dados do Departamento de Edificações e Rodovias (2009). A fruticultura irrigada da região Metropolitana tomou-se como base a atividade exercida no município de Maranguape, que dista $30 \mathrm{~km}$ do mercado central, sediado em Fortaleza, conforme informações do Departamento de Edificações e Rodovias (2009).

\subsection{Caracterização dos cenários}

Os cenários foram formulados a partir da implementação de políticas que propiciem redução nas diferenças de competitividade das atividades produtivas desenvolvidas nas áreas cearenses de fruticultura irrigada, que pode ser resultante da redução nos custos de transferência por meio de melhorias na infraestrutura de transportes, de mudança tecnológica, que pode ser poupadora de mão de obra e insumos, de mudança organizacional, proveniente do desenvolvimento de networks sociais, e da ação conjunta dessas medidas de intervenção. 
Nesse contexto, o cenário 1 foi construído com base na redução dos custos de transferência do deslocamento das frutas das áreas irrigadas para o ponto-base, com consequente redução nas diferenças de competitividade, obtidas por meio da promoção de melhores condições na infraestrutura, como construção e recuperação da malha rodoviária. Essas melhorias refletem tanto o encurtamento do percurso entre as áreas irrigadas e o ponto-base como reduções nos custos dos fretes entre essas regiões. Para compor esse cenário, foram considerados os programas de governo e ações, definidos no Plano Plurianual 2008-2011 da Secretaria de Planejamento e Gestão (Fortaleza, 2007, 2008) do Governo do estado do Ceará, referentes à logística de transporte, mais precisamente aos relacionados às melhorias no sistema rodoviário cearense. Dentre esses programas, destacou-se a construção da rodovia Padre Cícero que liga as regiões do Cariri e do Centro-Sul à Fortaleza, com reduções da distância e do tempo de viagem.

Dados do Departamento de Edificações e Rodovias (2009) do Ceará, a construção da rodovia Padre Cícero propiciou redução de 9,35\% e 7\%, respectivamente, da distância entre Fortaleza e o Cariri, representado pelo município de Juazeiro do Norte, e entre a capital cearense e o Centro-Sul, representado pelo município de Iguatu, em relação ao percurso atual via BR-116. Portanto, considerou-se que a redução dos custos de transferência entre as frutas dessas regiões e o ponto-base proveniente da construção dessa rodovia seja expressa por esses percentuais especificados.

As diferenças de competitividade também podem ser reduzidas por meio da adoção de tecnologias mais sofisticadas de adubação, como a fertirrigação, que possibilita a aplicação de adubos e fertilizantes por meio da irrigação (cenário 2). Segundo Mantovani et al. (2003), a adoção desse método apresenta vantagens como melhoria da eficiência, possibilidade de redução na dosagem de nutrientes, maior aproveitamento do equipamento de irrigação, menores impactos ambientais pelo melhor uso dos nutrientes no solo quando aplicados por meio de irrigação localizada e redução de mão de obra.

A partir da pesquisa de campo realizada junto aos agentes rurais, técnicos agrícolas, engenheiros agrônomos, dirigentes de empresas, presidentes de associações e secretários de agricultura, foram colhidas informações concernentes aos tipos de frutas produzidas, quantidade de plantas por hectare, área (em ha.), produtividade anual ( $\mathrm{kg} / \mathrm{ha}$.), preço ( $\mathrm{R} \$ / \mathrm{kg})$, sistema de irrigação adotado, custos de produção com mão de obra e com insumos agrícolas e tipo de fertilizante utilizado. De posse desses dados, foi possível identificar os sistemas produtivos das atividades frutícolas. Rastreando os tipos de frutas produzidas nas regiões irrigadas analisadas, encontraram-se: banana-prata no Baixo Acaraú, no Baixo Jaguaribe e no Cariri; banana-pacová no Baixo Jaguaribe, no Centro-Sul, na Ibiapaba e Metropolitana; mamão no Baixo Acaraú, Baixo Jaguaribe e Metropolitana; goiaba no Baixo Jaguaribe, Cariri, Centro-Sul e Metropolitana; melão no Baixo Acaraú; melancia no Baixo Acaraú; manga no Baixo Acaraú e Cariri; uva no Cariri e Centro-Sul; acerola na Ibiapaba e Metropolitana; maracujá no Baixo Acaraú, Ibiapaba e Metropolitana. Desses 25 setores analisados, dez (banana-pacová no Centro-Sul, Ibiapaba e Metropolitana; mamão na região Metropolitana; goiaba no Centro-Sul e Metropolitana; uva no Centro-Sul; acerola na região Metropolitana; e maracujá na Ibiapaba e Metropolitana) não fizeram adubação por meio da irrigação, porém podem empregá-la. Portanto, esses setores foram considerados na simulação de redução de custos com insumos e com mão de obra resultante da fertirrigação.

Nesse contexto, é relevante ressaltar que a simulação de mudança tecnológica não incidiu diretamente sobre o Baixo Acaraú, representado pelo perímetro público federal com mesmo nome, o Baixo Jaguaribe, que contém os perímetros públicos federais Tabuleiro de Russas e 
Jaguaribe Apodi, e o Cariri, já que constituem as áreas irrigadas frutícolas mais desenvolvidas do Ceará, que servem como referenciais para as demais.

Com base em informações coletadas com agentes econômicos que detêm conhecimentos práticos do uso dessas técnicas, a incorporação desse sistema pode reduzir, em média, 15\% dos custos com insumos, porém esse decréscimo depende do tipo de sistema de irrigação adotado (microaspersão ou gotejamento), do tipo de fertilizante utilizado e do tipo de solo cultivado. Esse percentual de redução foi adotado no cenário 2 uniformemente nesses setores, mas foram desconsideradas as variações quanto ao tipo de sistema de irrigação localizado, tipo de fertilizante e tipo de solo cultivado.

Quanto aos custos com mão de obra, sua redução decorrente do emprego dessa tecnologia depende do espaçamento e da densidade de cada cultura adotada na região. Por exemplo, no caso da manga, cuja densidade é de 350 plantas por hectare, requer poucas aplicações de adubos, logo o custo de uma adubação manual é em torno de $2 \%$. Em contrapartida, o melão que possui densidade média de 16.667 plantas por hectare apresenta maior dispêndio com mão de obra, em torno de $15 \%$. Neste trabalho, a mensuração do percentual de redução dos custos com mão de obra foi determinada em termos proporcionais à densidade populacional da cultura frutícola especificada para cada região. Com base nessas características, foram simuladas reduções de custos com mão de obra de $2 \%$ para banana-pacová na Ibiapaba e Metropolitana; goiaba no Centro-Sul e Metropolitana; acerola na região Metropolitana; 4\% para banana-pacová e uva no Centro-Sul; e maracujá, na Ibiapaba e Metropolitana; e 6\% para mamão na região Metropolitana.

Outra forma de se reduzir as diferenças de competitividade relativa das atividades produtivas nas áreas cearenses de fruticultura irrigada contemplou mudanças em sua estrutura organizacional. A partir da caracterização dos sistemas produtivos das atividades frutícolas obtida mediante pesquisa de campo, observou-se a existência de integração vertical entre produtores dentro da área irrigada, como são os casos da banana-prata anã, banana pacovan e mamão no Baixo Jaguaribe, em que se verificou a presença de parcerias entre produtores familiares e grandes empresas sediadas nessa região, como a Frutacor. Essa integração também é perceptível com a acerola orgânica na região da Ibiapaba, em que fruticultores de pequeno porte são produtores parceiros da empresa multinacional Nutrilite. Portanto, tais atividades foram diretamente influenciadas com a aplicação desse choque. Com base nessas condições de integração, elaborou-se o cenário 3, que permitiu verificar os impactos da formação de networks sociais, como associação de produtores, para aumentar o poder de barganha em suas relações comerciais com tais agentes de comercialização. A operacionalização dessa simulação requereu que a magnitude do poder de mercado fosse mensurada. Esse poder de mercado foi obtido pela diferença entre a participação dos custos de transferência e dos custos de transporte no valor total da produção. Os custos de transferência correspondem à diferença entre o preço médio do produto no ponto-base e o preço médio vigente nas áreas irrigadas para cada uma das atividades consideradas e os custos de transporte referem-se aos fretes pagos para transportar as frutas de cada região produtora para o mercado central sediado na capital cearense. Para implementação desse cenário, considerou-se que o percentual repassado para os fruticultores fosse $50 \%$ do poder de mercado médio dos setores que fazem parte da simulação. Nesse caso, o poder de mercado médio para esses setores foi $13 \%$, logo foram avaliados os impactos dessa simulação, se $6,5 \%$ desse poder de mercado fosse repassado para seus produtores, com o intuito de minimizar os impactos resultantes das imperfeições de mercado presentes nas atividades frutícolas. Finalmente, no cenário 4, avaliaram-se os impactos provenientes das simulações simultâneas de redução nos custos de transferência 
(construção da rodovia Padre Cícero versus a BR-116), das mudanças tecnológicas e das novas formas organizacionais.

O Quadro 2 apresenta a especificação dos cenários avaliados com as atividades envolvidas e os percentuais considerados em cada simulação.

Quadro 2 - Síntese dos cenários

\begin{tabular}{|c|c|c|c|c|}
\hline Tipo de Cenário & & Especificação & Atividades envolvidas & $\begin{array}{l}\text { Percentuais } \\
\text { considerados }\end{array}$ \\
\hline \multirow{2}{*}{$\begin{array}{l}\text { Redução nos custos } \\
\text { de transferência }\end{array}$} & \multirow{2}{*}{1} & \multirow{2}{*}{$\begin{array}{l}\text { Rodovia Padre } \\
\text { Cícero via BR-116 }\end{array}$} & Frutas C & $9,35 \%(\mathrm{~T})$ \\
\hline & & & Frutas CS & $7 \%(\mathrm{~T})$ \\
\hline Mudança tecnológica & 2 & Uso da fertirrigação & $\begin{array}{l}\text { Frutas CS, I e M, com } \\
\text { exceção de acerola I }\end{array}$ & $2 \%$ a $6 \%(L)$ e $15 \%(I)$ \\
\hline $\begin{array}{l}\text { Mudança } \\
\text { organizacional }\end{array}$ & 3 & Integração vertical & $\begin{array}{l}\text { Banana-prata anã e } \\
\text { pacovan BJ; Mamão BJ; } \\
\text { Acerola I }\end{array}$ & $6,5 \%$ \\
\hline $\begin{array}{l}\text { Redução nos custos } \\
\text { de transferência } \\
\text { e mudanças } \\
\text { tecnológicas e } \\
\text { organizacionais }\end{array}$ & 4 & $\begin{array}{l}\text { Ação conjunta dos } \\
\text { cenários } 1,2 \text { e } 3\end{array}$ & $\begin{array}{l}\text { Frutas C, CS, I e M, com } \\
\text { exceção de acerola l; } \\
\text { Banana-prata anã e } \\
\text { pacovan BJ; Mamão BJ }\end{array}$ & $\begin{array}{l}\text { Percentuais dos } \\
\text { cenários } 1,2 \text { e } 3 .\end{array}$ \\
\hline
\end{tabular}

Nota: BJ, Baixo Jaguaribe; C, Cariri; CS, Centro-Sul; I, Ibiapaba; M, Metropolitana. T, transporte; N, terra; L, trabalho; I, outros insumos. Fonte: Dados da pesquisa.

\section{Resultados e Discussão}

A análise foi realizada para 25 setores e mostrou os impactos dessas simulações sobre os níveis de produção e os preços desses setores em relação ao equilíbrio inicial. As alterações no bem-estar e na renda dos agentes econômicos, resultantes da implementação desses cenários, também foram avaliadas. Ademais, foi realizada uma avaliação global do comportamento dessas variáveis quando se considerou a ação conjunta dessas simulações.

Em função do choque de redução nos custos de transferência no Cariri e no Centro-Sul, captados pelo cenário 1, verificou-se que a produção de frutas nessas regiões apresentou acréscimo, conforme se observa na Tabela 3.

Tabela 3 - Variação percentual da produção de frutas e dos preços resultantes da implementação dos cenários 1, 2 e 3 em relação ao equilíbrio inicial

\begin{tabular}{|c|c|c|c|c|c|c|}
\hline \multirow{2}{*}{ Setores } & \multicolumn{2}{|c|}{ Cenário 1} & \multicolumn{2}{|c|}{ Cenário 2} & \multicolumn{2}{|c|}{ Cenário 3} \\
\hline & Produção & Preço & Produção & Preço & Produção & Preço \\
\hline Banana-prata BA & 0,000 & 0,005 & 0,000 & 0,017 & 0,000 & $-0,037$ \\
\hline Banana-prata BJ & 0,000 & 0,005 & 0,000 & 0,014 & 0,000 & $-0,037$ \\
\hline Banana-prata C & 0,025 & $-0,015$ & 0,000 & 0,016 & 0,000 & $-0,037$ \\
\hline Banana-pacová BJ & 0,000 & 0,005 & 0,000 & 0,018 & 0,000 & $-0,037$ \\
\hline Banana-pacová CS & 0,019 & $-0,011$ & 0,062 & $-0,030$ & 0,005 & $-0,037$ \\
\hline Banana-pacová I & 0,000 & 0,004 & 0,057 & $-0,028$ & $-0,009$ & $-0,037$ \\
\hline Banana-pacová M & 0,000 & 0,004 & 0,049 & $-0,017$ & 0,001 & $-0,037$ \\
\hline Mamão BA & 0,000 & 0,002 & 0,000 & 0,027 & 0,000 & $-0,037$ \\
\hline
\end{tabular}

Fonte: dados da pesquisa. Nota: BA = Baixo Acaraú; BJ = Baixo Jaguaribe; $\mathrm{C}=$ Cariri; $\mathrm{CS}$ = Centro-Sul; I = Ibiapaba; e M = Metropolitana. 
Tabela 3 - Continuação...

\begin{tabular}{|c|c|c|c|c|c|c|}
\hline \multirow{2}{*}{ Setores } & \multicolumn{2}{|c|}{ Cenário 1} & \multicolumn{2}{|c|}{ Cenário 2} & \multicolumn{2}{|c|}{ Cenário 3} \\
\hline & Produção & Preço & Produção & Preço & Produção & Preço \\
\hline Mamão BJ & 0,000 & 0,002 & 0,000 & 0,024 & 0,000 & $-0,037$ \\
\hline Mamão M & 0,000 & 0,003 & 0,053 & $-0,018$ & 0,006 & $-0,037$ \\
\hline Goiaba BJ & 0,000 & 0,004 & 0,000 & 0,022 & 0,000 & $-0,037$ \\
\hline Goiaba C & 0,032 & $-0,023$ & 0,000 & 0,023 & 0,000 & $-0,037$ \\
\hline Goiaba CS & 0,022 & $-0,015$ & 0,047 & $-0,012$ & 0,010 & $-0,037$ \\
\hline Goiaba M & 0,000 & 0,004 & 0,044 & $-0,011$ & 0,004 & $-0,037$ \\
\hline Melão BA & 0,000 & 0,006 & 0,000 & 0,013 & 0,000 & $-0,037$ \\
\hline Melancia BA & 0,000 & 0,005 & 0,000 & 0,020 & 0,000 & $-0,037$ \\
\hline Manga BA & 0,000 & 0,005 & 0,000 & 0,021 & 0,000 & $-0,037$ \\
\hline Manga C & 0,027 & $-0,018$ & 0,000 & 0,020 & 0,000 & $-0,037$ \\
\hline Uva C & 0,028 & $-0,019$ & 0,000 & 0,016 & 0,000 & $-0,037$ \\
\hline Uva CS & 0,019 & $-0,010$ & 0,081 & $-0,054$ & $-0,009$ & $-0,037$ \\
\hline Acerola I & 0,000 & 0,005 & 0,001 & 0,023 & 0,022 & $-0,037$ \\
\hline Acerola M & 0,000 & 0,004 & 0,055 & $-0,025$ & $-0,003$ & $-0,037$ \\
\hline Maracujá BA & 0,000 & 0,004 & 0,000 & 0,020 & 0,000 & $-0,037$ \\
\hline Maracujá I & 0,000 & 0,005 & 0,058 & $-0,028$ & $-0,005$ & $-0,037$ \\
\hline Maracujá M & 0,000 & 0,005 & 0,057 & $-0,025$ & 0,001 & $-0,037$ \\
\hline
\end{tabular}

Fonte: dados da pesquisa. Nota: BA = Baixo Acaraú; BJ = Baixo Jaguaribe; C = Cariri; CS = Centro-Sul; I = Ibiapaba; e M = Metropolitana.

A aplicação desse choque, porém, não ocasionou efeitos sobre as produções de frutas nas demais regiões analisadas. Essa evidência é coerente com a prática, já que a construção dessa rodovia não beneficiou diretamente tais regiões. No tocante ao comportamento dos preços, observou-se redução de preços nos setores frutícolas que tiveram menores custos associados com a transferência das frutas nesse cenário avaliado. Esse barateamento nos preços, resultante da redução nos custos de transferência, gerou ganho de competitividade e estimulou o crescimento da oferta dessas frutas, o que pode ser considerada uma absorção do frete por parte dos produtores. Isso promoveu um acréscimo na produção desses setores. A partir da implementação do cenário 3 resultante das mudanças organizacionais, verificou-se que os recursos provenientes da aquisição do poder de mercado foram redistribuídos entre as atividades dentro da área irrigada contemplada. Nesse novo equilíbrio, para que os agentes econômicos possam maximizar suas funções de utilidade e de lucro, todos os níveis de preços foram reduzidos na mesma proporção dos custos com os fatores terra, trabalho, transferência e outros insumos (Tabela 3).

Em termos agregados, a redução nos custos de transferência promovida pela construção da rodovia propiciou acréscimo de $0,52 \%$ na produção de frutas, o que corresponde a um aumento anual de $\mathrm{R} \$ 311.329,14$. Esse valor sinaliza a importância da infraestrutura de transporte, que possibilitou a minimização de custos para transferir produtos entre regiões, impulsionando o crescimento econômico. A expansão da produção requer mais mão de obra, o que resulta em aumento da remuneração do fator trabalho. Um maior volume de produção demanda mais gastos com o processo de transferência. Somente os outros insumos têm seus preços reduzidos devido à natureza do progresso tecnológico (Tabela 4). 
Tabela 4 - Variação percentual nos preços dos fatores resultantes da aplicação dos cenários 1, 2 e 3, em relação ao equilíbrio inicial

\begin{tabular}{|c|c|c|c|}
\hline Fatores & Cenário 1 & Cenário 2 & Cenário 3 \\
\hline Terra na região do Baixo Acaraú & 0,005 & 0,020 & $-0,037$ \\
\hline Terra na região do Baixo Jaguaribe & 0,005 & 0,018 & $-0,037$ \\
\hline Terra na região do Cariri & 0,035 & 0,017 & $-0,037$ \\
\hline Terra na região do Centro-Sul & 0,028 & 0,099 & $-0,037$ \\
\hline Terra na região da Ibiapaba & 0,005 & 0,075 & $-0,037$ \\
\hline Terra na região Metropolitana & 0,004 & 0,087 & $-0,037$ \\
\hline Trabalho & 0,010 & 0,033 & $-0,037$ \\
\hline Transferência & $-0,009$ & 0,049 & $-0,037$ \\
\hline Outros insumos & 0,012 & $-0,018$ & $-0,036$ \\
\hline
\end{tabular}

Fonte: dados da pesquisa.

Constatou-se que as terras do Cariri e do Centro-Sul se tornaram mais atrativas com a redução nos custos de transferência dessas regiões, já que os fruticultores dessas áreas se sentiram mais motivados a expandirem suas explorações para auferirem maior rentabilidade (Tabela 4). Nas demais regiões, as variações nos preços da terra foram desprezíveis e servem apenas para promoverem o ajustamento do modelo. Para o fator trabalho, a intensificação do uso da terra no Cariri e Centro-Sul resultou em elevação da remuneração da mão de obra.

Diante da mudança tecnológica resultante do uso da fertirrigação, verificou-se redução dos custos com insumos e com mão de obra em relação ao equilíbrio inicial. Como a incorporação dessa técnica reduz os custos unitários com mão de obra e fertilizantes, se espera que os setores que empregarem a fertirrigação apresentem impactos positivos sobre as produções. Essa tendência foi verificada em todos os setores produtivos envolvidos nesse cenário. Quanto aos outros setores enfocados, os dados mostraram que suas produções não se modificaram em relação ao equilíbrio inicial, sendo condizente com o esperado, visto que essas atividades produtivas já empregavam o sistema de fertirrigação. Ademais, constatou-se que o crescimento agregado no nível de atividade produtiva da economia regional, proveniente da fertirrigação, expresso em termos de valores, foi de 2,43\%, o que representou aumento de $\mathrm{R} \$ 1.442 .575,25$. A magnitude desse valor demonstra a relevância dessa inovação tecnológica para os fruticultores cearenses. Portanto, é importante a atuação de políticas públicas, como concessão de crédito, que permitam aos produtores agrícolas terem acesso a esse tipo de técnica. Quando os produtores de frutas se organizam em associações, cooperativas ou outro formato de networks sociais e passam a ser menos dependentes das decisões tomadas nas estruturas de mercado oligopolista e oligopsonista, eles podem destinar seus recursos às atividades mais competitivas, obtendo maiores rentabilidades.

Quanto à renda desses agentes econômicos, constatou-se que, no cenário 1, apenas o transportador (TRANSP) teve sua renda reduzida com tal redução nos custos de transferência, porém os demais agentes foram beneficiados, inclusive os fruticultores das outras regiões que não foram diretamente contemplados com essa melhoria de transporte. Conforme esperado, o crescimento da renda foi mais notório para os produtores de frutas do Cariri (FRUT 3), com acréscimo de 3,5\%, e do Centro-Sul (FRUT 4), com ganhos de 2,8\% (Figura 2). 


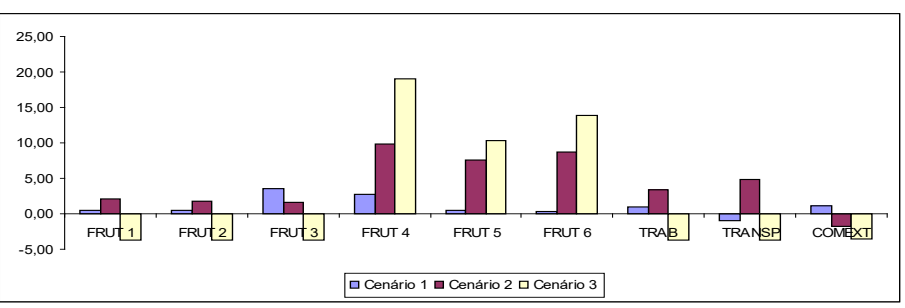

Figura 2 - Variação percentual na renda dos agentes representativos, provenientes da redução nos custos de transferência (cenário 1) e mudanças tecnológicas (cenário 2) e organizacional (cenário 3), em relação ao equilíbrio inicial. Fonte: dados da pesquisa.

A inovação tecnológica (cenário 2) propiciou acréscimo na renda para todos os fruticultores das regiões consideradas, sendo mais expressivos para os localizados no Centro-Sul (FRUT 4), Ibiapaba (FRUT 5) e Metropolitana (FRUT 6), que foram diretamente beneficiados com a incidência desse choque. Os trabalhadores e os transportadores também se beneficiaram com esse cenário, visto que tal simulação gerou expansão nos níveis de atividades. Em outros termos, dentre os agentes considerados, o único que teve redução em seus rendimentos foi o fornecedor de insumos, já que a adoção da fertirrigação permitiu que os produtores de frutas destinassem menos recursos para a aquisição de fertilizantes.

Como se verifica, os produtores, que dispuseram de menores recursos tecnológicos do Centro-Sul, Ibiapaba e Metropolitana, tiveram ganhos de renda em decorrência de terem sido contemplados com a mudança organizacional (cenário 3). Esses impactos positivos de renda foram mais expressivos do que os decréscimos ocorridos para os demais agentes investigados.

Pela Figura 3 observa-se que, no cenário 1, o acréscimo no bem-estar mais notável incidiu sobre os fruticultores do Cariri e do Centro-Sul. Os trabalhadores e o fornecedor de insumos também obtiveram ganhos de bem-estar nessa simulação. $O$ transportador, porém, apresentou redução no bem-estar, que está associada ao decréscimo em sua renda, devido à queda no custo de transferência. Entretanto, é perceptível que a variação positiva de bem-estar dos fruticultores do Cariri e do Centro-Sul, do trabalhador e do fornecedor de insumos representativos se sobrepôs à variação negativa, captada pelo transportador.

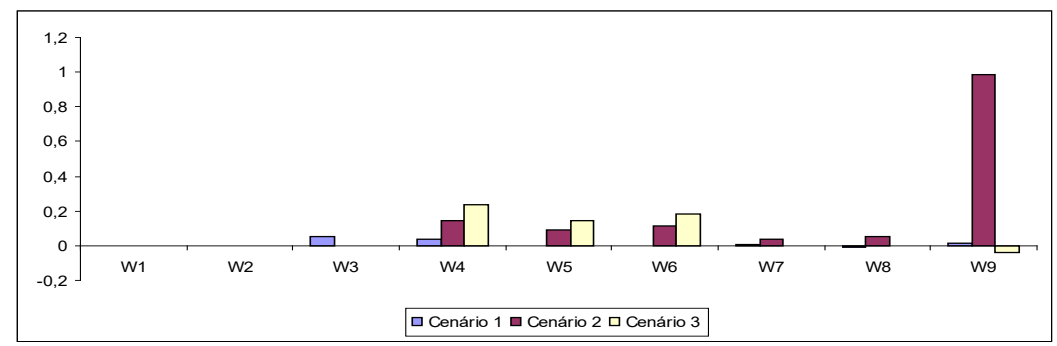

Figura 3 - Variação percentual no bem-estar dos agentes representativos, provenientes de redução nos custos de transferência (cenário 1) e mudanças tecnológica (cenário 2) e organizacional (cenário 3), em relação ao equilíbrio inicial. Fonte: dados da pesquisa.

Comparando as Figuras 2 e 3, verifica-se que os benefícios obtidos pelos fruticultores do Baixo Acaraú (FRUT 1), Baixo Jaguaribe (FRUT 2) e Cariri (FRUT 3), com a mudança tecnológica (cenário 2), foram completamente diluídos pelo acréscimo dos preços. Quanto aos demais consumidores, apesar dos níveis de bem-estar terem seguido o mesmo sentido da renda, constatou-se que suas variações percentuais foram menores que da renda, sinalizando que parcela considerável do crescimento da renda foi absorvida pelo aumento de preços. 
A Figura 3 também mostra que os fruticultores das regiões 4, 5 e 6 tiveram os ganhos mais notáveis de bem-estar resultantes da apropriação do maior poder de mercado. Em contrapartida, conforme esperado, os agentes de comercialização tiveram seus níveis de bem-estar reduzidos, já que obtiveram menores níveis de renda resultantes da própria natureza da simulação. Ademais, verificou-se que, apesar de os preços de todos os fatores terem se reduzido, esse decréscimo foi totalmente repassado para os preços das atividades, não gerando, portanto, ganhos de bem-estar. Desta forma, a maior parte dos ganhos de renda obtidos por esses agentes econômicos foi dissolvida via redução de preços.

Após a avaliação dos impactos resultantes das simulações de redução nos custos de transferência com a construção da rodovia Padre Cícero sobre a BR-116 (cenário 1), de mudanças tecnológicas poupadoras de terra, trabalho e insumos (cenário 2) e de mudanças organizacionais provenientes da formação de networks sociais (cenário 3), também se mensuraram os impactos globais da atuação concomitante desses choques (cenário 4).

Em resposta a essas ações conjuntas, verificou-se que os níveis de atividades aumentaram, devendo ser ressaltado que os setores que mais se destacaram foram os localizados no CentroSul, visto que essas atividades receberam benefícios simultâneos de redução dos custos de transferência e de mudanças tecnológicas e organizacionais. Em contrapartida, os setores sediados no Cariri registraram variações positivas nos níveis de atividades com valores menores, já que foram contemplados exclusivamente pela redução nos custos de transferência. Dentre esses cenários investigados, nenhum deles incidiu diretamente sobre as atividades do Baixo Acaraú e do Baixo Jaguaribe, logo esses setores não se modificaram com a aplicação desses choques. Em decorrência do acréscimo nos níveis de atividades dos setores analisados, houve queda nos níveis de preços, que está associada, sobretudo, à redução dos preços dos outros insumos (Tabela 5).

Tabela 5 - Variação percentual da produção de frutas e dos preços resultantes da implementação do cenário 4, em relação ao equilíbrio inicial

\begin{tabular}{lccccc}
\multicolumn{1}{c}{ Setores } & Produção & Preço & Setores & Produção & Preço \\
Banana-prata BA & 0,000 & $-0,015$ & Goiaba M & 0,049 & $-0,043$ \\
Banana-prata BJ & 0,000 & $-0,018$ & Melão BA & 0,000 & $-0,019$ \\
Banana-prata C & 0,026 & $-0,037$ & Melancia BA & 0,000 & $-0,012$ \\
Banana-pacová BJ & 0,000 & $-0,014$ & Manga BA & 0,000 & $-0,012$ \\
Banana-pacová CS & 0,089 & $-0,077$ & Manga C & 0,028 & $-0,035$ \\
Banana-pacová I & 0,048 & $-0,060$ & Uva C & 0,029 & $-0,041$ \\
Banana-pacová M & 0,051 & $-0,050$ & Uva CS & 0,094 & $-0,099$ \\
Mamão BA & 0,000 & $-0,009$ & Acerola I & 0,022 & $-0,010$ \\
Mamão BJ & 0,000 & $-0,011$ & Acerola M & 0,053 & $-0,057$ \\
Mamão M & 0,060 & $-0,051$ & Maracujá BA & 0,000 & $-0,013$ \\
Goiaba BJ & 0,000 & $-0,011$ & Maracujá I & 0,053 & $-0,059$ \\
Goiaba C & 0,033 & $-0,038$ & Maracujá M & 0,059 & $-0,057$ \\
Goiaba CS & 0,083 & $-0,064$ & & & \\
\hline
\end{tabular}

Fonte: dados da pesquisa. Nota: $\mathrm{BA}=$ Baixo Acaraú; $\mathrm{BJ}=$ Baixo Jaguaribe; $\mathrm{C}=$ Cariri; $\mathrm{CS}=$ Centro-Sul; I = Ibiapaba; e M = Metropolitana.

Apesar do crescimento agregado no nível de produção ter apresentado pequena magnitude em termos relativos, esse acréscimo, em termos absolutos, representou aumento, expresso em termos de valores, de $\mathrm{R} \$ 1.766 .590,97$. Esse valor evidencia a importância da atuação conjunta dessas simulações. 
Ao avaliar a variação porcentual da renda dos agentes econômicos resultante da atuação conjunta das simulações realizadas, observa-se que os maiores benefícios foram usufruídos pelos produtores das regiões Centro-Sul (FRUT 4), Ibiapaba (FRUT 5) e Metropolitana (FRUT 6), com ganhos de 31,53, 17,97 e 22,51\%, respectivamente (Figura 4).

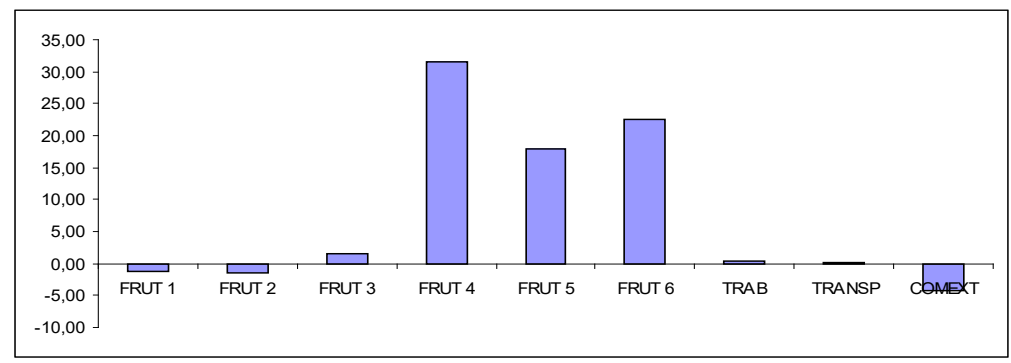

Figura 4 - Variação percentual na renda dos agentes representativos, proveniente da ação conjunta de redução nos custos de transferência e mudanças tecnológicas e organizacionais, em relação ao equilíbrio inicial. Fonte: dados da pesquisa.

Verifica-se que os fruticultores das regiões 4, 5 e 6 mantiveram sua posição de destaque como os maiores beneficiários do aumento de bem-estar quando a atuação conjunta das simulações efetivadas foi avaliada (Figura 5). Em termos de variações relativas, porém, constatou-se que parcela majoritária dos acréscimos de renda, obtida por esses produtores, não foi convertida em melhorias de bem-estar.

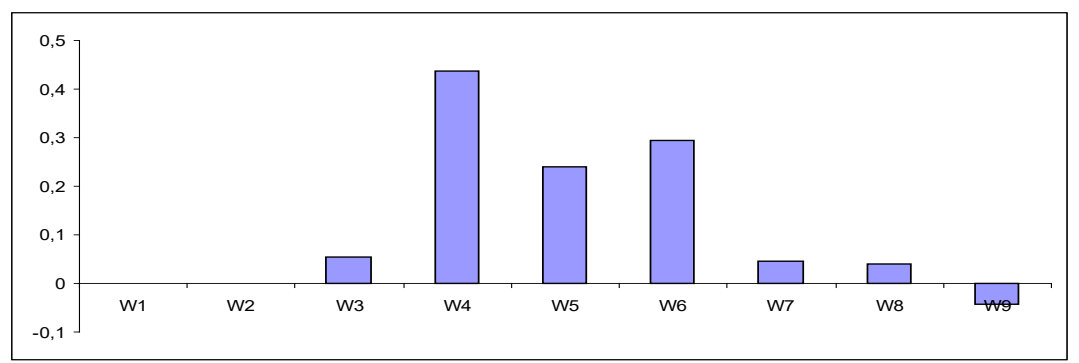

Figura 5 - Variação percentual no bem-estar dos agentes representativos, proveniente da ação conjunta de redução nos custos de transferência e mudanças tecnológicas e organizacionais, em relação ao equilíbrio inicial. Fonte: dados da pesquisa.

Ademais, é relevante destacar que variações no bem-estar foram sendo compensadas pelas elevações de preços, enquanto as elevações nos níveis de renda apresentaram valores mais altos. Nesse trabalho, em particular, variações na renda foram melhores indicadores de uma situação mais desejada, tendo em vista que a matriz de contabilidade social considerada não incorporou dados sobre a economia externa a essas regiões. Ganhos de renda desses fruticultores representaram possibilidades de alcançarem níveis de consumo e bem-estar mais elevados, quando expostos à economia externa.

\section{Conclusões}

A fruticultura irrigada cearense tem apresentado crescente importância na geração de emprego, renda e divisas, consolidando-se como um dos principais segmentos exportadores do estado, com produção de alimentos de maior valor agregado. Para tornar a atividade mais 
competitiva, tem-se empregado processo produtivo com base em tecnologias mais sofisticadas. Mesmo com a adoção de novas tecnologias e das políticas de capacitação para os agentes produtivos e de promoção comercial, verificou-se que essas atividades representam fontes de imperfeições do mercado, em que os fruticultores deparam-se com uma estrutura oligopolista na compra de insumos modernos e uma estrutura oligopsonista na venda de frutas produzidas nas áreas irrigadas cearenses.

Em virtude da dispersão espacial da produção, esses produtores defrontam-se com processos de formação de preços para insumos e produtos que geram custos de transferências diferenciados entre essas regiões. Nesse ambiente, diferenças no grau de competitividade entre as atividades produtivas podem resultar em taxas de rentabilidade que favoreçam o desenvolvimento da produção em uma região em detrimento das outras. Essas condições prevaleceram nas regiões de fruticultura irrigada do Baixo Acaraú, Baixo Jaguaribe, Cariri, Centro-Sul, Ibiapaba e Metropolitana, que foram as áreas consideradas nesse trabalho. Diante desse contexto, buscou-se avaliar como melhorias tecnológicas, organizacionais e de infraestrutura de transporte podem contribuir para reduzir as diferenças de competitividade entre as atividades produtivas desenvolvidas nas regiões cearenses de fruticultura irrigada.

Os resultados da simulação de redução nos custos de transferência mostraram variações positivas nos níveis das atividades produtivas nas regiões beneficiadas e, como consequência, redução em seus preços, o que indica que esses setores se tornam mais competitivos com a aplicação desse choque. Com menores custos para transferir frutas dessas regiões para 0 ponto-base, os produtores se sentem mais motivados a expandirem suas explorações para auferirem maior rentabilidade. Desta forma, demandam mais mão de obra e outros insumos, fazendo com que seus preços aumentem e ocasionem elevação nos custos das atividades produzidas nas outras regiões produtoras.

A partir da implementação do cenário de mudança tecnológica, constatou-se expansão nos níveis de atividades dos setores impactados, o que resultou em menores preços. Os setores sediados nas demais regiões, porém, tiveram seus preços aumentados devido à incorporação dessa tecnologia ter tornado a terra mais produtiva, requerendo mais utilização dos fatores trabalho e transferência. No tocante à mudança na forma organizacional, observou-se que os recursos provenientes da aquisição desse poder de mercado foram redistribuídos entre as atividades dentro da área irrigada contemplada. Nesse novo equilíbrio, para que os agentes econômicos pudessem maximizar suas funções de utilidade e de lucro, todos os níveis de preços foram reduzidos na mesma proporção dos custos com os fatores terra, trabalho, transferência e outros insumos.

Verificou-se também que, em todos os cenários avaliados, os níveis de bem-estar acompanharam o sentido da alteração da renda, mas suas variações percentuais foram muito menores do que as ocorridas com a renda, indicando que parcela considerável do crescimento da renda foi absorvida pela variação de preços.

Ademais, é relevante destacar que a ausência de associação entre a MCS regional adotada no trabalho e a MCS nacional pode ser ressaltada como uma limitação dessa pesquisa, em que as interações com a economia externa não foram consideradas nesse trabalho. Portanto, sugere-se, para pesquisas futuras, que o escopo do trabalho não se concentre nas transações comerciais entre as diferentes regiões produtoras e o ponto-base, mas também incluam as relações comerciais entre o ponto-base e a economia externa. Apesar dessa limitação, este estudo desempenhou importante função no sentido de identificar medidas potenciais de políticas públicas que podem reduzir as diferenças de competitividade entre as atividades produtivas desenvolvidas nas áreas cearenses de fruticultura irrigada. 


\section{Referências}

Almeida, E. S. (2003). Um modelo de equilíbrio geral aplicado espacial para planejamento e análise de políticas de transporte (Tese de doutorado). Universidade de São Paulo, São Paulo.

Almeida, E. S., \& Guilhoto, J. J. M. (2007). O custo de transporte como barreira ao comércio na integração econômica: o caso do Nordeste. Revista Economica do Nordeste, 38(2), 224-243.

Araújo, M. P. (2006). Infra-estrutura de transporte e desenvolvimento regional: uma abordagem de equilíbrio geral inter-regional(Tese de doutorado). Escola Superior de Agricultura “Luiz de Queiroz", Piracicaba.

Bröcker, J., Korzhenevych, A., \& Schümann, C. (2010). Assessing spatial equity and efficiency impacts of transport infrastructure projects. Transportation Research Part B: Methodological, 44(7), 795-811.

Campos, R. C., \& Haddad, E. (2016). A. Avaliação dos impactos espaciais do sistema viário Oeste/ Bahia: uma abordagem a partir da Modelagem de Equilíbrio Geral Computável. Revista Brasileira de Economia de Empresas, 16(2), 25-47.

Clemente, A., \& Higachi, H. Y. (2000). Economia e desenvolvimento regional. São Paulo.

Departamento de Edificações e Rodovias - DER. (2009). Distâncias rodoviárias. Recuperado em 19 de setembro de 2009, de http://www.dert.ce.gov.br

Departamento Nacional de Obras Contra as Secas - DNOCS. (2009). Perímetros irrigados. Recuperado em 18 de junho de 2009, de http://apoena.dnocs.gov.br/ apoena//php/ projetos/projetos.php

Diário do Nordeste. (2014, abril 6). Fruticultura cearense é destaque em todo País. Fortaleza.

Edwards, M. E. (2007). Regional and urban economics and economic development: theory and methods. London: Taylor \& Francis.

Elshahawany, D. N., Haddad, E. A., \& Lahr, M. (2017). Accessibility, transportation cost, and regional growth: a case study for Egypt. Middle East Development Journal, 9(2), 256-277.

Espinosa, M. P. (1992). Delivered pricing, FOB pricing and collusion in spatial markets. The Rand Journal of Economics, 23(1), 64-85.

Fortaleza. Secretaria de Planejamento e Gestão - SEPLAG. (2007). Plano plurianual 2008-2011 (Vol. I). Fortaleza.

Fortaleza. Secretaria de Planejamento e Gestão - SEPLAG. (2008). Plano plurianual 2008-2011 (Vol. II). Fortaleza.

Fujita, M., Krugman, P., \& Venables, A. (1999). The spatial economy: cities, regions and international trade. Cambridge: MIT Press.

Graubner, M., Balmann, A., \& Sexton, R. J. (2011). Spatial price discrimination in agricultural product procurement markets: a computational economics approach. American Journal of Agricultural Economics, 93(4), 949-967.

Greenhut, M. L., Norman, G., \& Hung, C.-S. (1987). The economics of imperfect competition: a spatial approach. Cambridge: Cambridge University Press.

Haddad, E. A. (2004). Retornos crescentes, custos de transporte e crescimento regional (Tese de livre docência). Universidade de São Paulo, São Paulo.

Haddad, E. A. (2006). Transporte, eficiência e desigualdade regional: avaliação com um modelo CGE para o Brasil. Pesquisa e Planejamento Economico, 36(3), 413-448.

Haddad, E. A., Perobelli, F. S., Domingues, E. P., \& Aguiar, M. (2011). Assessing the ex ante economic impacts of transportation infrastructure policy in Brazil. Journal of Development Effectiveness, 3(1), 44-61. 
Haddad, P. R. (1989). Economia regional: teorias e métodos de análise. Fortaleza: Banco do Nordeste do Brasil.

Haddock, D. D. (1982). Basing-Point Pricing: competitive vs. collusive theories. The American Economic Review, 72(3), 289-306.

Kellerman, A. (1989). Agricultural location theory, 2: relaxation of assumptions and applications. Environment \& Planning A, 21, 1427-1448.

Khemani, S., \& Shapiro, D. M. (1993). Glossary of industrial organization economics and competition law. Paris: Directorate for Financial, Fiscal and Enterprise Affairs, OECD.

Kim, E., \& Hewings, G. J. D. (2003). An application of integrated transport network-multiregional CGE model II: calibration of network effects of highway. Regional Economics Applications Laboratory, University of Illinois.

Krugman, P. (1991). Increasing returns and economy geography. Journal of Political Economy, 99(3), 483-499.

Krugman, P., \& Venables, A. J. (1996). Integration, specialization, and adjustment. European Economic Review, 40, 959-967.

Lofgren, H., \& Robinson, S. (2002). Spatial-network, general-equilibrium model with a stylized application. Regional Science and Urban Economics, 32, 651-671.

Mantovani, E. C., Zinato, C. E., \& Simão, F. R. (2003). Manejo de irrigação e fertirrigação na cultura da goiabeira. In D. E. Rozane \& F. A. A. Couto (Eds.), Cultura da goiabeira: tecnologia e mercado. Viçosa: UFV; EJA.

Oliveira, F. Z. (2009). Comunicação oral. Fortaleza: ADECE.

Pequeno, R. S. A., \& Dantas, J. T. (2007). A internacionalização do espaço norte-rio-grandense: um estudo sobre o Pólo de Desenvolvimento Integrado Assú-Mossoró. In Anais do $5^{\circ}$ Encontro Nacional da Associação Brasileira de Estudos Regionais e Urbanos. Recife. CD-ROM.

Rabêlo, A. N. (2006). Contribuição ao estudo da imprimação betuminosa das bases rodoviárias do Estado do Ceará (Dissertação de mestrado). Universidade Federal do Ceará, Fortaleza.

Sabadia, F. R. B., Araújo, J. P. P., Oliveira, F. Z., \& Barcellos, C. V. (2006). A experiência de Agropolos do Ceará: impactos no desenvolvimento do agronegócio da agricultura irrigada. Fortaleza: Instituto Agropolos do Ceará.

Sakamoto, H. (2012). CGE analysis of transportation cost and regional economy: East Asia and Northern Kyushu. Regional Science Inquiry Journal, 4(1), 121-140.

Scherer, F. M. (1980). Industrial market structure and economic performance. Chicago: Rand McNally.

Vassallo, M. D. (2015). Análise de impactos econômicos setoriais e regionais decorrentes de investimentos em infraestrutura de transportes (Tese de doutorado). Universidade de São Paulo, São Paulo.

Vieira, W. C. (1998). Notas sobre a construção de Matrizes de Contabilidade Social. Economia Rural, 9(2), 30-37. 